\title{
PENERAPAN METODE WATERFALL PADA PENGEMBANGAN APLIKASI SISTEM INFORMASI JASA DAN PENJUALAN DENGAN PEMODELAN BERORIENTASI OBJEK
}

\author{
Jauhari Maulani ${ }^{1)}$ \\ Fakultas Teknologi Informasi, Universitas Islam Kalimantan Muhammad Arsyad Al Banjari Banjarmasin \\ Email : jauharimaulani@gmail.com
}

\begin{abstract}
Abstrak
Pada butik husna busana semula hanya menyediakan usaha jasa pembuatan pakaian, kini sudah merambah juga dalam usaha penjualan. Sebelumya sistem informasi yang telah berjalan pada butik tersebut hanya untuk transaksi jasa pembuatan pakaian saja, yang mana pada penelitian sebelumnya pembuatan sistem informasi jasa pembuatan pakaian melakukan transaksi proses pendataan pelanggan data pelanggan, data ukuran pakaian pelanggan, progres pakaian dibuat atau sudah selesai serta perhitungan periode pendapatan hasil transaksi dibuat dalam laporan perperiode pelaporan. pada masa digunakannya aplikasi sistem informasi jasa pembuatan pakaian masih terdapat adanya kekurangan proses yang bisa lebih meningkatkan performa aplikasi tersebut, maka perlunya pengembangan aplikasi sistem informasi pada butik husna busana agar adanya sistem yang saling terintegrasi antara transaksi jasa dan penjualan barang. Dalam pengembangan aplikasi sistem informasi jasa dan penjualan pada butik husna busana akan diterapkan metode waterfall, yang mana penerapan tersebut dilakukan muilai dari tahapan perencanaan, analisis, perancangan, implementasi dan penggunaan serta dilaksanakan dengan pemodelan berorientasi objek yang mana antar pihak butik dan pelanggan saling berinteraksi memberikan informasi terhadap satu sama lainnya. Dari hasil penerapan metode waterfall pada pengembangan aplikasi sistem informasi jasa dan penjualan dengan pemodelan berorientasi objek menghasilkan kemudahan dan keringkasan dalam hal transaksi dan Pengolahan pendataan penjualan lebih efektif dan efisien.
\end{abstract}

Kata Kunci: Sistem Informasi, waterfall, jasa dan penjualan

\section{PENDAHULUAN}

Pada era industri 4.0 aplikasi sistem informasi dizaman sekarang ini semakin berkembang yang mana sudah digunakan diberbagai kalangan guna mempermudah aktivitas serta transaksi para pengguna. Seiring itu pada butik husna busana yang semula hanya menyediakan usaha jasa pembuatan pakaian, kini sudah merambah juga dalam usaha penjualan kain, aksesoris dan pakaian.

Sebelumya sistem informasi yang telah berjalan pada butik tersebut hanya untuk transaksi jasa pembuatan pakaian saja, yang mana pada penelitian sebelumnya pembuatan sistem informasi jasa pembuatan pakaian melakukan transaksi proses pendataan pelanggan data pelanggan, data ukuran pakaian pelanggan, progres pakaian dibuat atau sudah selesai serta perhitungan periode pendapatan hasil transaksi dibuat dalam laporan perperiode pelaporan.

Dari masa penggunaan pada tahapan akhir metode waterfall, pada masa digunakannya aplikasi sistem informasi jasa pembuatan pakaian masih terdapat adanya kekurangan proses yang bisa lebih meningkatkan peforma aplikasi tersebut, salah satunya penambahan progres pengerjaan pakaian, penambahan pengingat batas waktu informasi selesainya pakaian yang telah 
dijanjikan. Selain itu adanya perluasan usaha dari butik husna busana yang telah merambah usaha penjualan maka aplikasi sistem informasi yang telah ada dapat dikembangkan juga dengan penambahan proses penginputan data barang yang dijual, serta transaksi penjualannya melalui sistem informasi website nantinya.

Berdasarkan latarbelakang masalah yang telah ada, maka perlunya pengembangan aplikasi sistem informasi pada butik husna busana agar adanya sistem yang saling terintegrasi antara transaksi jasa dan penjualan barang. Dalam pengembangan aplikasi sistem informasi jasa dan penjualan pada butik husna busana akan diterapkan metode waterffall, yang mana penerapan tersebut dilakukan muilai dari tahapan perencanaan, analisis, perancangan, implementasi dan penggunaan, serta dilaksanakan dengan pemprograman berorientasi objek yang mana antar pihak butik dan pelanggan saling berinteraksi memberikan informasi terhadap satu sama lainnya.

\section{METODE PENELITIAN}

\section{Aplikasi}

Dari banyak pengertian tentang aplikasi dapat disimpulkan bahwa aplikasi adalah sebuah program komputer yang dibuat untuk menolong manusia dalam melaksanakan tugas tertentu. Ada banyak pengertian mengenai aplikasi oleh para ahli yaitu:

a. Menurut Buyens, (2001) Aplikasi adalah satu unit perangkat lunak yang dibuat untuk melayani kebutuhan akan beberapa aktivitas.

b. Menurut Post, (1999) Aplikasi adalah sistem lengkap yang mengerjakan tugas spesifik.

Menurut Kroenke, (1990) Aplikasi basis data terdiri atas sekumpulan menu, formulir, laporan dan program yang memenuhi kebutuhan suatu fungsional unit bisnis/organisasi/instansi.

\section{Sistem Informasi}

Merancang sistem informasi menjadi bagian dari proses rekayasa perangkat lunak. Sistem Informasi Manajemen (SIM) dapat didefinisikan sebagai suatu alat untuk menyajikan informasi dengan cara sedemikian rupa sehingga bermanfaat bagi penerimanya (Kertahadi, 1995). Tujuannya adalah untuk menyajikan informasi guna pengambilan keputusan pada perencanaan, pemrakarsaan, pengorganisasian, pengendalian kegiatan operasi subsistem suatu perusahaan dan menyajikan sinergi organisasi pada proses (Murdick dan Ross, 1993).

\section{Pemodelan Berorientasi Objek}

Perancangan dan pembangunan aplikasi perangkat lunak berbasis objek sedang marak digunakan saat ini dengan menganggap segala sesuatunya adalah objek serta sistem dipandang sebagai interaksi dari banyak objek menjadi ide utama pendekatan ini. Perancangan berbasis objek dimeodelkan menggunakan Unified Modelling Language (UML). UML merupakan kumpulan diagram diagram yang sudah memiliki standar untuk pembanguanan perangkat lunak berbasis objek.

\section{Siklus pengembengan sistem informasi / SDLC}

Siklus pengembengan sistem informasi / SDLC identik dengan istilah metode air terjun (Waterfall Method). Setiap tahap akan mempengaruhi dan menjadi dasar dari keberlangsungan tahap pengembangan berikutnya, sama seperti air terjun yang mengalir dari atas kebawah. Tahap baru akan dilakukan setelah tahap sebelumnya rampung dan kesalahan tahap sebelumnya akan berdampak kuat pada tahap berikutnya.

\section{Metode WATERFAL}

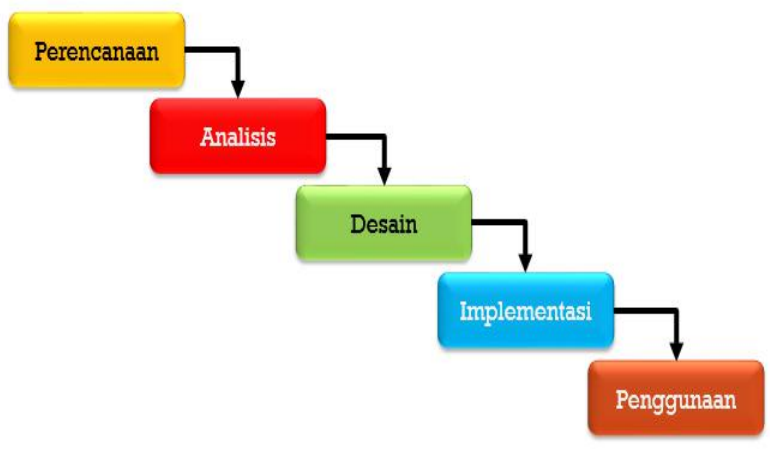

Gambar 1.Tahapan Metode Air Terjun (Waterfall Method) 
kwitansi tulis tangan sebagai bukti transaksi pembelian untuk pelanggan.

\section{Perencanaan Pengembangan Aplikasi}

Adanya perluasan usaha dari butik husna busana yang telah merambah usaha penjualan maka aplikasi sistem informasi yang telah ada dapat dikembangkan juga dengan penambahan proses penginputan data barang yang dijual, serta transaksi penjualannya melalui sistem informasi website nantinya.

\section{Analisis Prosedur Sistem}

Pada tahap Analisis ini tim peneliti lebih Memahami SOP (Standard Operational Procedure), alur kerja dari sistem yang ada pada butik tersebut, dari alur sistem jasa dan penjualannya. Tahap analisis perluanya identifikasi atau investigasi yang lebih mendalam untuk mengkaji sistem agar memperoleh data yang diperlukan dalam penyusunan penelitian ini, dengan menggunakan metode pengumpulan data sebagai berikut:

\section{Wawancara}

Melakukan tanya jawab langsung kepada pihak butik Husna Busana tentang bagaimana keberlangsungan sistem informasi yang telah ada dan sedang berjalan pada tempat tersebut guna analisis untuk mengembangkan kembali aplikasi sistem informasi pada penelitian ini. Salah satunya tentang penualan produk baik pakaian/kain dan lainnya, sebelumnya dilakukan dengan penjualan ditempat dan diposting melalui media sosial. Dari wawancara tersebut pihak butik menyatakan bahwa banyak transaksi yang tidak tercatat dengan baik.

\section{Pengamatan Langsung}
Mengamati langsung proses pengumpulan data, transaksi jasa dan penjualan yang telah dilakukan oleh pihak butik menggnakan pencatatan pada buku besar atau catatan yang menuliskan data barang dan modal serta penjualan yang dilakukan menggunakan nota atau

3. Studi Pustaka

Pengumpulan data dengan menggunakan buku-buku dan pencarian artikel jurnal di internet sebagai bahan referensi dalam penulisan laporan dan pembuatan sistem.

\section{Perancangan Alur Sistem}

Pengembangan Aplikasi Sistem Informasi Jasa dan Penjualan dengan Pemprograman Berorientasi Objek dirancang dengan Permodelan Berorientasi Objek menggunakan Unified Modeling Langguage (UML), dan penggambaran model UML digambarkan dalam Diagram sebagai berikut :

\section{Use Case Aplikasi}

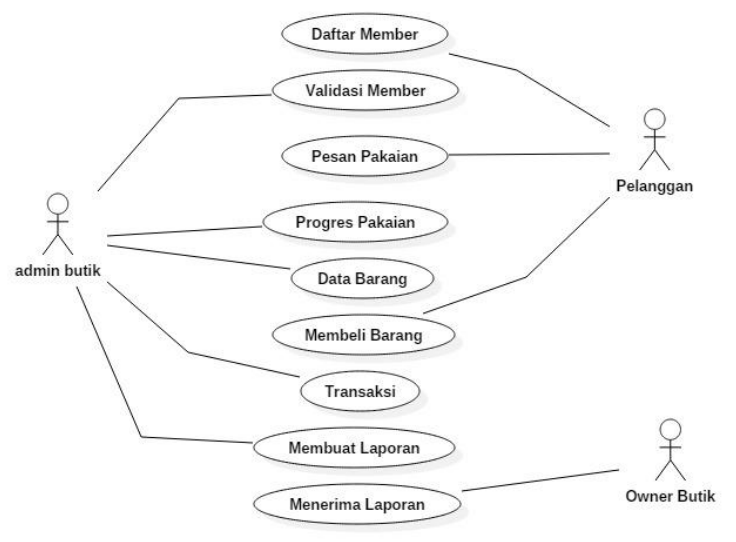

Gambar 2. Usecase Aplikasi

Usecase diagram diatas menunjukan akses apa saja yang bisa dilakukan oleh aktor (admin butik, Pelanggan dan Owner Butik) 


\section{Diagram Activity}

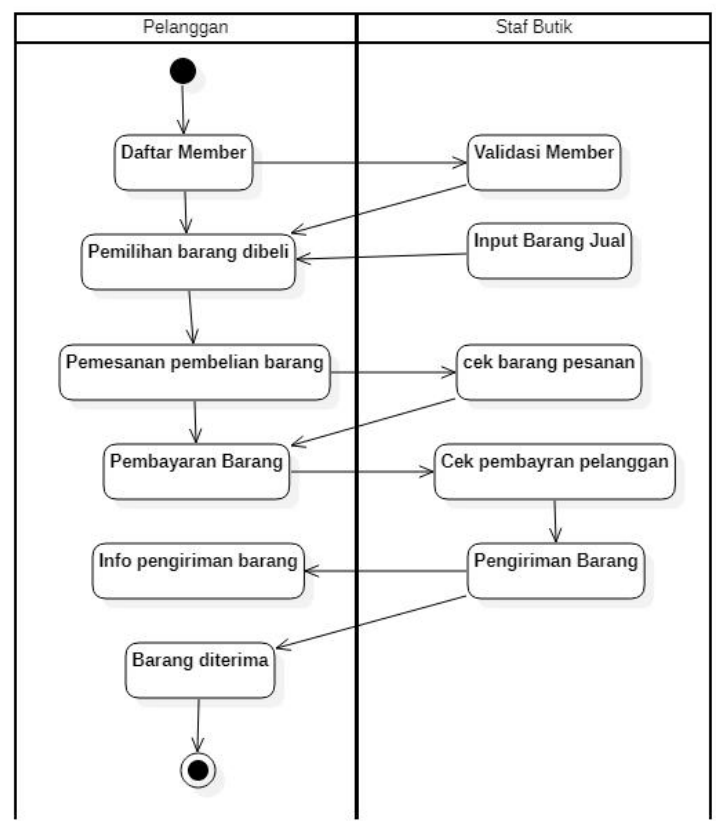

Gambar 3. Diagram Activity

Diagram Activity diatas menunjukan urutan aktivitas yang dilakukan dari beberapa tahapan antar pelanggan dan staf butik.

\section{Squence Diagram}

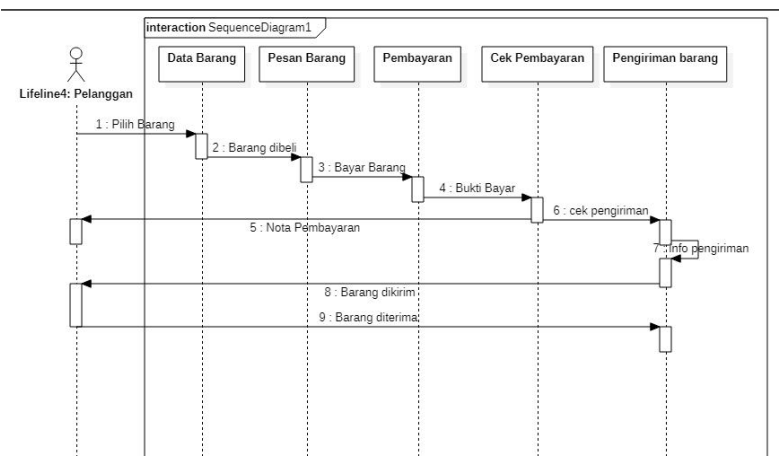

Gambar 4. Squence Diagram

Sequence diagram diatas mendeskripsikan interaksi antar objek, skenario atau tahapan rangkaian alur sistem dari loginnya pelanggan pada aplikasi butik hingga transaksi pembelian barang serta respon yang terjadi pada sistem.

\section{Mockup Rancangan Aplikasi}

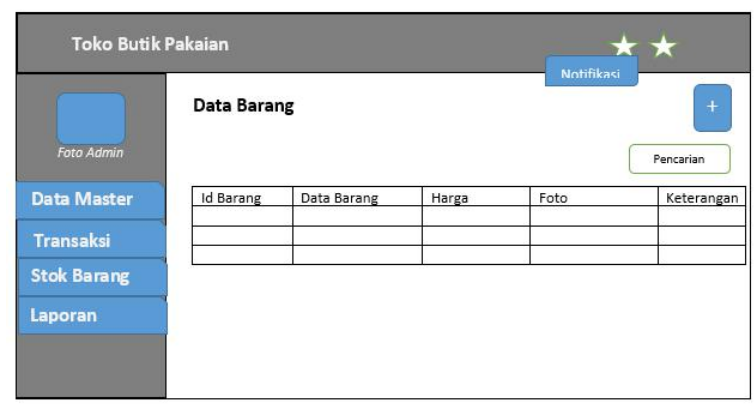

Gambar 5. Mockup Tampilan Aplikasi

Penggambaran mockup rancangan aplikasi ini sebagai acuan user interface agar lebih mudah dalam menganalisa penempatan tata letak menu aplikasi, desain dan fungsi.

\section{HASIL DAN PEMBAHASAN}

\section{Implementasi Pengembangan Aplikasi}

Tahap implementasi pengembangan aplikasi sistem informasi jasa dan penjualan dengan pemprograman berorientasi objek ini setelah dilakukan dengan perancangan model berorientasi objek yang mana di gambarkan dengan menggunakan Unified Modeling Langguage (UML), sebagai kerangka acuan kerja programer untuk mengimplementasikan pembuatan aplikasi menjadi sebuah sistem informasi yang bisa memprmudah dalam transaksi butik husna busana

\section{Tampilan Menu Awal Aplikasi}

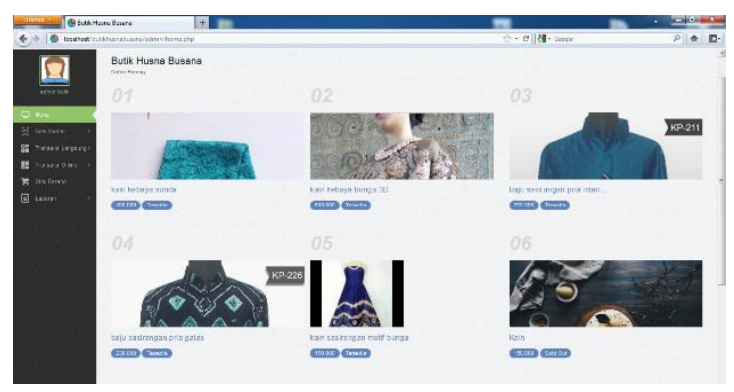

Gambar 6. Tampilan Awal Dasboard Admin

Pada tampilan awal menu aplikasi ini terdapat tampilan daftar barang yang dijual, notifikasi penjualan, menu data master, transaksi langsung (transaksi yang dilakukan langsung pada toko butik tersebut), dan 
transaksi online (penjualan melalui online), stok barang serta menu laporan.

\section{Tampilan Data Barang}

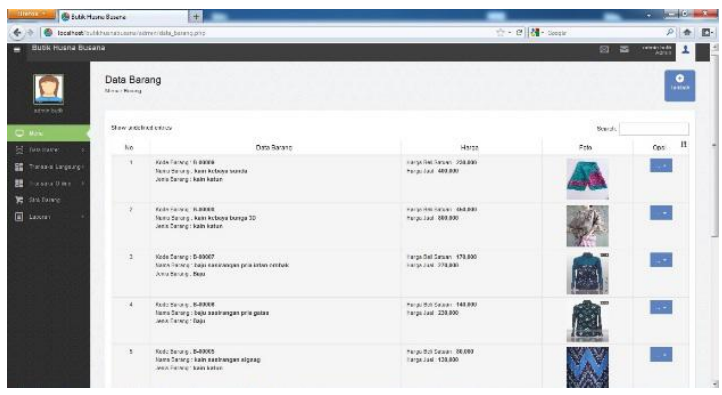

Gambar 7. Tampilan Data Barang

Pada tampilan data barang diatas berfungsi sebagai penginput data barang serta penginputan harga beli dan harga jual produk barang tersebut.

\section{Tampilan Home Pada Member}

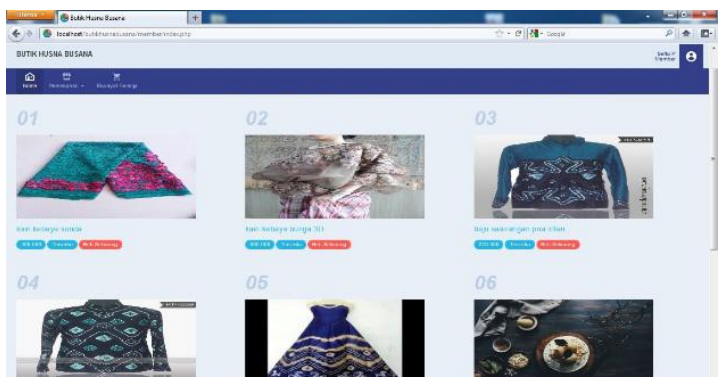

Gambar 8. Tampilan Hompage Member

Berikut tampilan awal pada sisi pelanggan/member, menampilkan data penjualan produk barang, jadi pelanggan bisa memilih langsung produk pada halaman tersebut.

\section{Notifikasi Penjualan Online}

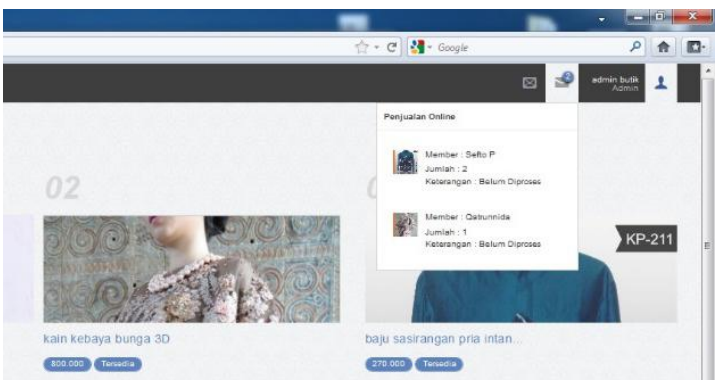

Gambar 9. TampilanNotifikasi

Pada bagian sudut kanan atas terdapat icon pesan dan tanda pemberitahuan notifikasi penjualan yang harus dicek untuk dikonfirmasi.

\section{Konfirmasi Penjualan Online}

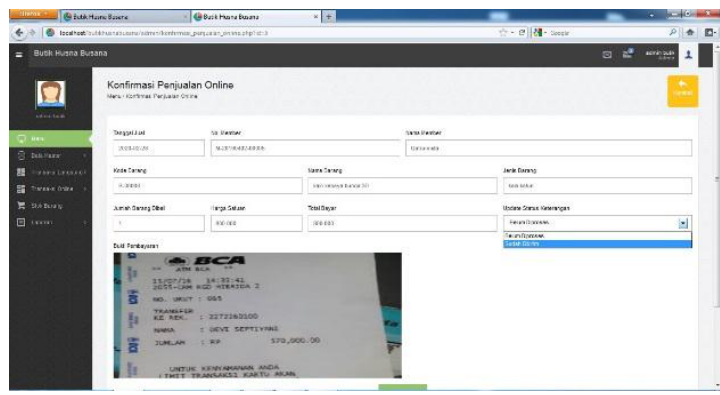

Gambar 10. Tampilan Konfirmasi Status

Pada tampilan diatas terdapat form konfirmasi penjualan online, jadi pada bagian ini pihak butk (admin butik mengkonfirmasi pembayaran barang ) dan kalau sudah pasti cek barang dan pembayaran langsung dikonfirmasi barang sudah dikirim.

\section{Data Transaksi Penjualan}

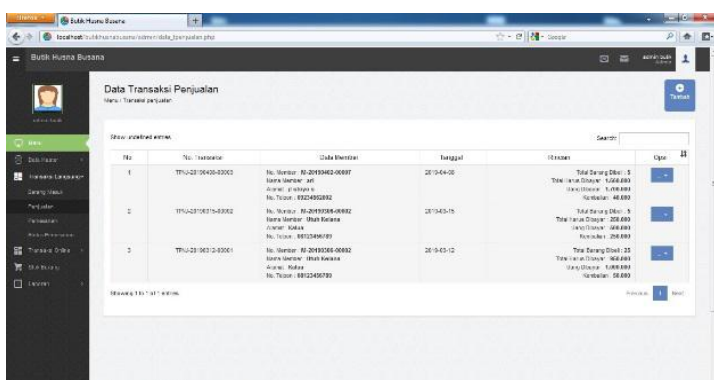

Gambar 11. Tampilan Data Transaksi Penjualan

Pada tampilan data transaksi penjualan diatas terlihat hasil semua transaksi penjualan, dari no transaksi, data pembeli, tanggal serta rincian pembayaran barang yang di jual.

\section{Pengujian dan Penggunaan Aplikasi}

Sebelum aplikasi masuk pada tahap penggunaan pengujian dilakukan terlebih dahulu oleh analis sistem. Pengujian ini dilakukan menggunakan black box testing. 
Tabel 1. Tabel Pengujian Aplikasi

\begin{tabular}{|c|c|c|c|c|c|}
\hline $\begin{array}{c}\text { Test Case } \\
\text { Description }\end{array}$ & Test Case & $\begin{array}{c}\text { Expected } \\
\text { Result }\end{array}$ & $\begin{array}{l}\text { Actual } \\
\text { Result }\end{array}$ & Kesimpulan & Tampilan Aplikasi \\
\hline $\begin{array}{l}\text { Pengguna Login } \\
\text { Sebagai Admin }\end{array}$ & $\begin{array}{l}\text { User : admin } \\
\text { Pass: } 1234\end{array}$ & \begin{tabular}{l|} 
Sistem akan \\
berpindah ke \\
halaman \\
tampilan awal \\
aplikasi \\
dasboard \\
admin \\
\end{tabular} & \begin{tabular}{|l|} 
Sistem \\
berpindah ke \\
halaman \\
tampilan awal \\
aplikasi \\
dasboard \\
admin \\
\end{tabular} & Berhasil & 田 \\
\hline $\begin{array}{l}\text { Pengguna Login } \\
\text { Sebagai Member }\end{array}$ & $\begin{array}{l}\text { User: member } \\
\text { Pass: } 1234\end{array}$ & $\begin{array}{l}\text { Sistem akan } \\
\text { berpindah ke } \\
\text { halaman } \\
\text { tampilan awal } \\
\text { aplikasi } \\
\text { dasboard } \\
\text { member }\end{array}$ & $\begin{array}{l}\text { Sistem } \\
\text { berpindah ke } \\
\text { halaman } \\
\text { tampilan awal } \\
\text { aplikasi } \\
\text { dasboard } \\
\text { member }\end{array}$ & Berhasil & sor \\
\hline $\begin{array}{l}\text { Admin } \\
\text { menambahkan } \\
\text { data } \\
\text { barang/produk } \\
\text { pada aplikasi }\end{array}$ & $\begin{array}{l}\text { Kode, nama } \\
\text { barang, jenis, } \\
\text { harga beli idan } \\
\text { harga jual }\end{array}$ & \begin{tabular}{l|} 
Sitem akan \\
menampilkan \\
data barang \\
berhasil \\
disimpan pada \\
database \\
aplikasi
\end{tabular} & \begin{tabular}{l|} 
Sitem \\
menampilkan \\
data barang \\
berhasil \\
disimpan pada \\
database \\
aplikasi
\end{tabular} & Berhasil & $\begin{array}{l}E=0 \\
E=\end{array}$ \\
\hline $\begin{array}{l}\text { Member } \\
\text { menambahkan } \\
\text { pembelian } \\
\text { barang/produk } \\
\text { pada aplikasi }\end{array}$ & $\begin{array}{l}\text { Jumlah beli dan } \\
\text { bukti } \\
\text { pembayaran }\end{array}$ & $\begin{array}{l}\text { Sitem akan } \\
\text { menampilkan } \\
\text { data barang } \\
\text { dibeli berhasil } \\
\text { disimpan pada } \\
\text { database } \\
\text { aplikasi } \\
\text { pembelian }\end{array}$ & $\begin{array}{l}\text { Sitem } \\
\text { menampilkan } \\
\text { data barang } \\
\text { dibeli berhasil } \\
\text { disimpan pada } \\
\text { database } \\
\text { aplikasi } \\
\text { pembelian }\end{array}$ & Berhasil & \\
\hline $\begin{array}{l}\text { Admin } \\
\text { mengkonfirmasi } \\
\text { pembelian } \\
\text { barang dari } \\
\text { member }\end{array}$ & $\begin{array}{l}\text { Admin } \\
\text { mengkonfirmasi } \\
\text { pada update } \\
\text { status } \\
\text { keterangan } \\
\text { Belum } \\
\text { diproses/sudah } \\
\text { dikirim }\end{array}$ & \begin{tabular}{l|} 
Sitem akan \\
menampilkan \\
konfirmasi \\
penjualan \\
online berhasil \\
disimpan pada \\
database \\
transaksi \\
online \\
\end{tabular} & \begin{tabular}{|l|} 
Sitem \\
menampilkan \\
konfifmasi \\
penjualan \\
online berhasil \\
disimpan pada \\
database \\
transaksi \\
online \\
\end{tabular} & Berhasil & \\
\hline $\begin{array}{l}\text { Member } \\
\text { melakukan } \\
\text { pengecekan pada } \\
\text { riwayat belanja }\end{array}$ & $\begin{array}{l}\text { Member melihat } \\
\text { data pembelian } \\
\text { barang vang } \\
\text { sudah dibeli atau } \\
\text { masih diproses } \\
\text { pembelian }\end{array}$ & $\begin{array}{l}\text { Sistem akan } \\
\text { menampilkan } \\
\text { riwayat } \\
\text { belanja data } \\
\text { daftar barang } \\
\text { yang dibeli }\end{array}$ & $\begin{array}{l}\text { Sistem } \\
\text { menampilkan } \\
\text { riwayat } \\
\text { belanja data } \\
\text { daftar barang } \\
\text { yang dibeli }\end{array}$ & Berhasil & $\bar{m}$ \\
\hline $\begin{array}{l}\text { Admin } \\
\text { melakukan } \\
\text { pengecekan } \\
\text { laporan data } \\
\text { transaksi } \\
\text { penjualan } \\
\end{array}$ & $\begin{array}{l}\text { Admin melihat } \\
\text { data pembelian } \\
\text { no transaksi, data } \\
\text { member, } \\
\text { tanggal, rincian }\end{array}$ & \begin{tabular}{|l|} 
Sistem akan \\
menampilkan \\
riwayat \\
belanja data \\
daftar barang \\
yang dibeli \\
\end{tabular} & $\begin{array}{l}\text { Sistem } \\
\text { menampilikan } \\
\text { riwayat } \\
\text { belanja data } \\
\text { daftar barang } \\
\text { yang dibeli }\end{array}$ & Berhasil & $\begin{array}{l}= \\
= \\
=\end{array}$ \\
\hline
\end{tabular}

Dari hasil pengujian yang telah dilakukan dengan menggunakan black box testing diatas, maka aplikasi sudah bisa masuk tahap penggunaan yang mana sistem sudah berjalan dengan lancar hingga memudahkan penggunaan transaksi dan pembuatan laporan transaksi pada butik husna busana. Hasil evaluasi pengembangan aplikasi sistem informasi yang telah di uji coba serta dilakukan penggunaan secara berkala maka hasil yang didapat :

1) Penginputan data barang atau produk penjualan berhasil menggunakan waktu input maksimal 2 menit per item barang.

2) Barang atau produk penjualan yang telah diinput bisa tampil didasboard member dan member bisa melakukan pembelian barang atau produk dengan waktu proses pembelian sekitar 3 menit.

3) Notifikasi pembelian bisa tersampaikan ke admin dengan waktu notif maksimal 1 menit dan admin melakukan pengecekan serta konfirmasi dengan maksimal waktu 4 menit per transaksi pembelian.

4) Sistem dapat membuat laporan transaksi satuan, perperiode serta keseluruhan dalam waktu maksimal 5 menit

\section{KESIMPULAN}

Berdasarkan dari hasil penerapan metode waterfall pada pengembangan aplikasi sistem informasi jasa dan penjualan dengan pemodelan berorientasi objek, maka dapat ditarik kesimpulan sebagai berikut :

1. Penerapan metode waterfall memudahkan pengembangan aplikasi sistem informasi dengan penyelesaian sesuai tahapan atau langkah yang sudah disusun mengurut rentetan tahapan metode waterfall.

2. Pengembangan aplikasi sistem informasi ke transaksi penjualan yang dibuat secara offline dan online dapat meningkatkan dan merapikan sistem penjualan.

3. Penginformasian mengenai status pembelian barang atau produk dapat dilihat langsung melalui website sistem informasi dengan adanya pemberitahuan berupa notifikasi antar admin dan member butik tersebut.

4. Pengolahan pendataan penjualan pada butik husna busana dari pencatatan pembukuan bertransformasi ke sistem berbasis website lebih efektif dan efisien dalam hal transaksi penjualan.

Dari kesimpulan yang telah didapat pada pengembangan aplikasi sistem informasi ini menghasilkan kemudahan dan keringkasan dalam hal transaksi. namun pengembangan ini masih banyak kekurang dalam hal sistem lainnya, maka saran untuk pengembangan penelitian selanjutnya sistem ini dapat dikembangkan lebih baik lagi, baik penambahan fitur sistem ataupun pengembangan ke sistem android kedepannya.

\section{DAFTAR PUSTAKA}

[1] A.S, Rosa. M. Shalahudin. (2010, Juli). Modul Pembelajaran Pemprograman Berorientasi Objek. Bandung. Modula.

[2] Alatas, Husein. (2015). Proyek Membangun Responsive Web Design dengan Bootstrap 3\&4. Yogyakarta. C.V Lokomedia.

[3] Terstruktur dan Berorientasi Objek. Bandung. Informatika 
[4] Maulani, J., \& Amin, M. (2019). RANCANG BANGUN SISTEM INFORMASI JASA PEMBUATAN PAKAIAN DENGAN ALGORITMA PEMPROGRAMAN TERSTRUKTUR. Technologia: Jurnal Ilmiah, 10(2), 85-91.

[5] Maulani, J. (2016). REKRUTMEN KARYAWAN CV. ANNISA MENGGUNAKAN APLIKASI TEST PISIKOTES DAN KEPRIBADIAN BERBASIS DELPHI. Technologia: Jurnal Ilmiah, 7(2).

[6] Maulani, J. (2019). APLIKASI KESEHATAN MENGGUNAKAN METODE EPIDEMIOLOGI SKRINING TES UNTUK KARYAWAN CV. ANNISA. Technologia: Jurnal Ilmiah, 10(1), 10-16.

[7] Pranata, Antony. 2005. Algoritma dan Pemrograman. Yogyakarta. J \& J Learning

[8] Pratama, I Putu Agus Eka. 2013. Sistem Informasi dan Implementasinya. Bandung. Informatika Bandung

[9] Pratama, S. (2019). PERANCANGAN SISTEM INFORMASI PERPUSTAKAAN BERBASIS WEB (STUDI KASUS PADA SMP N 1 KERTAK HANYAR). Prosiding HasilHasil Penelitian tahun 2019 DosenDosen Universitas Islam Kalimantan, 2019(15), 327-332.

[10] Pratama, S. (2019). APLIKASI JOB FAIR BERBASIS WEB PADA DINAS SOSIAL TENAGA KERJA DAN TRANSMIGRASI KALIMANTAN SELATAN. Technologia: Jurnal Ilmiah, 10(1), 47-52.

[11] Sulianta, Feri. 2019. Strategi Merancang Arsitektur Sistem Informasi Masa Kini. Jakarta. PT Elex Media Komputindo.

[12] Sadeli, Muhammad. 2013. Toko Baju Online dengan PHP dan MySQL.Palembang. Maxikom.

[13] Sibero, Alexander F.K. 2013. WEB Programming Power Pack. Yogyakarta. MediaKom. 